\title{
Prevalence and associated risk factors of undercorrected refractive errors among people with diabetes in Shanghai
}

\author{
Mengjun Zhu' ${ }^{1}$, Xiaowei Tong ${ }^{1}$, Rong Zhao ${ }^{2}$, Xiangui He ${ }^{1}$, Huijuan Zhao ${ }^{3}$ and Jianfeng Zhu ${ }^{1 *}$
}

\begin{abstract}
Background: To investigate the prevalence and risk factors of undercorrected refractive error (URE) among people with diabetes in the Baoshan District of Shanghai, where data for undercorrected refractive error are limited.

Methods: The study was a population-based survey of 649 persons (aged 60 years or older) with diabetes in Baoshan, Shanghai in 2009. One copy of the questionnaire was completed for each subject. Examinations included a standardized refraction and measurement of presenting and best-corrected visual acuity (BCVA), tonometry, slit lamp biomicroscopy, and fundus photography.

Results: The calculated age-standardized prevalence rate of URE was 16.63\% (95\% confidence interval [CI] 13.76-19. 49). For visual impairment subjects (presenting vision worse than 20/40 in the better eye), the prevalence of URE was up to $61.11 \%$, and $75.93 \%$ of subjects could achieve visual acuity improvement by at least one line using appropriate spectacles. Under multiple logistic regression analysis, older age, female gender, non-farmer, increasing degree of myopia, lens opacities status, diabetic retinopathy (DR), body mass index (BMI) index lower than normal, and poor glycaemic control were associated with higher URE levels. Wearing distance eyeglasses was a protective factor for URE.

Conclusion: The undercorrected refractive error in diabetic adults was high in Shanghai. Health education and regular refractive assessment are needed for diabetic adults. Persons with diabetes should be more aware that poor vision is often correctable, especially for those with risk factors.
\end{abstract}

Keywords: Undercorrected refractive error, Diabetes, Visual impairment, Causes, China

\section{Background}

According to recent estimates by the International Diabetes Federation, the worldwide diabetes prevalence has reached $8.3 \%$, and approximately 382 million adults have had diabetes [1]. In China, the recent data show that the prevalence of diabetes in adults aged 20 years or older has increased to an alarming $11.6 \%$ [2]. The population size of Chinese patients with diabetes is estimated to be 92.4-98.4 million, and the incidence of diabetes has strongly increased $[1,3]$. Persons with diabetes are more likely to be visually impaired [4] and may have ocular complications, such as diabetic retinopathy (DR), which is the leading cause of visual impairment (VI). As

\footnotetext{
* Correspondence: jfzhu1974@hotmail.com

'Shanghai Eye Disease Prevention and Treatment Center, No. 380 Kangding

Road, Jingan District, Shanghai 200040, China

Full list of author information is available at the end of the article
}

a result, for a long time, the public health strategies for diabetic people in China were early detection and treatment of the ocular complications of diabetes. Recently, a study indicated that nearly two-thirds of adults with diabetes who had visual impairment could correct their vision with an accurate corrective prescription for glasses or contact lenses [4]. To date, data regarding the prevalence of undercorrected refractive errors in the diabetic population in China are scarce. Shanghai is an ageing society, and the use of the elderly as our study population was motivated by several additional considerations. First, the prevalence of URE is relatively high in the elder population [4]. Second, most people $\geq 60$ y in Shanghai have retired, and their enumeration can be more easily obtained from the official resident register than for younger people. The elderly are more prone to falls, and low vision has been documented to increase 
this risk [5, 6]; thus, visual correction is helpful for reducing the risk of injury and improving quality of life [7]. Therefore, the present study aimed to estimate the prevalence and associated risk factors for undercorrected refractive errors in people with diabetes. These data will be essential to the guidance and evaluation of public health policies designed to reduce the burden of visual impairment among elderly persons with diabetes in China.

\section{Methods}

\section{Study population}

The study subjects were recruited from the Baoshan Eye Study, which was a community-based, cross-sectional study of vision and eye diseases among subjects 60 years of age and above in Dachang, Shanghai, China. Baoshan District, with a population of 864,346 as of December 31,2009 , is located in the north of Shanghai. This area is representative of regions that are experiencing progressive urbanization as a result of China's rapid economic growth. The study design and research methodology have been described in detail previously [8]. Based on previous studies, the prevalence of URE was anticipated to be $21.7 \%$ [9], and the allowable error bound to be $20 \%$ with $95 \%$ confidence levels. An $85 \%$ response rate and a design effect of 1.5 were used to calculate the requisite sample size of 611 (according to the formula $\mathrm{N}$ $\left.=\mathrm{Z}^{2}(\mathrm{p})(1-\mathrm{p}) / \mathrm{B}^{2} \quad(p=0.217, \quad \mathrm{~B}=0.217 \times 0.20, \quad \mathrm{Z}=1.96)\right)$. Overall, 743 persons who were identified as diabetic according to the registered medical records of the residents' committee and community hospitals were eligible for the study. Vacant households, residents who died before being contacted, inpatients, subjects who refused to participate in the examination, and those who suffered from deafness or mental retardation were excluded. Finally, 680 subjects participated in this study. The current investigation followed the tenets of the Declaration of Helsinki and was approved by the Ethical Committee of the Shanghai Eye Disease Prevention and Treatment Center. All participants signed written informed consent before participating in the study.

\section{Enumeration and examination procedures}

The study consisted of a structured questionnaire used to obtain baseline information on demographic data (age, gender, occupation, insurance, and education level), personal medical history (diabetes mellitus, hypertension, hyperlipidaemia, cardiovascular disease previously diagnosed by a physician, and duration and treatment of corresponding disease), family history of eye diseases, wearing and availability of glasses, and lifestyle (smoking and alcohol intake).

Standardized ophthalmic examinations beginning with a visual acuity (VA) test were performed by ophthalmologists, optometrists, and technicians. Presenting VA (with spectacles if worn) and VA after refractive correction were measured using a $\operatorname{logMAR}$ chart with tumbling $\mathrm{E}$ at a distance of $4 \mathrm{~m}$. Autorefraction (Topcon KR-8900, Japan) was performed for all subjects independent of the VA. A subjective refraction exam was performed only for those with VA worse than $16 / 20$. Slit lamp examination, tonometry, and a dilated biomicroscopic fundus examination were performed by ophthalmologists. Digital monoscopic photographs of the optic disc and macula were obtained (Canon CR6-45 nm, Japan). All fieldwork was conducted from October 2009 to December 2009.

In the overall study group $(n=680)$, refraction was not performed on 2 subjects (due to the blind eye), and we referred to their former refractive record. Thus, refraction data were available for all 680 subjects. The fundus could not be observed clearly in 10 subjects because of the effect of lens opacities. Hence, if DR or other fundus diseases had been diagnosed by a physician previously, we recorded yes. If no relevant diagnosis had been made before, we recorded no. We also excluded 31 (12.9\%) subjects who had a history of cataract surgery and were either pseudophakic or aphakic. Finally, 649 subjects were included in this study. All subjects underwent measurement of systolic and diastolic blood pressure $(\mathrm{mmHg})$, height, and weight. We also recorded the glycosylated haemoglobin of all subjects, which was examined by community hospitals within 1 week of study commencement. Fasting blood sugar estimation was not performed in this study.

\section{Definitions}

Undercorrected refractive error was defined as a presenting visual acuity in the better eye worse than 6/12, with an improvement of at least 2 lines in BCVA compared to the presenting visual acuity [9]. The World Health Organization categories of vision loss were used to define blindness and severe visual impairment [10]. For mild and moderate visual impairment, a similar definition was used, which has been published in previous studies [11, 12]. Blindness was defined as a VA (with glasses for distance if normally worn or unaided if glasses for distance not worn) of $<3 / 60$ in the better eye. Severe visual impairment (SVI) was defined as a VA of $<6 / 60$ to $3 / 60$ in the better eye. Moderate visual impairment (Mod VI) was defined as a VA of $<6 / 18$ to $6 / 60$ in the better eye.

Mild visual impairment (Mild VI) was defined as a VA of $<6 / 12$ to $6 / 18$ in the better eye. Emmetropia was defined as a spherical equivalent between $-0.50 \mathrm{D}$ and $+0.50 \mathrm{D}$ [12]. Myopia was defined as a spherical equivalent of less than $-0.50 \mathrm{D}$, and hyperopia was defined as a spherical equivalent of greater than $+0.50 \mathrm{D}$. For further analysis, myopia was classified into the following three 
groups: mild ( -0.5 to $-3.0 \mathrm{D})$, moderate $(>-3.0$ to -6.0 $\mathrm{D})$, and severe (>-6.0 D). Grading of lens opacities was performed using the Lens Opacities Classification System (LOCS) III (LOCS chart III, Leo T. Chylack, Harvard Medical School, Boston, MA). Significant cortical and posterior subcapsular opacification was defined as greater than grade 2, and significant nuclear opacification was defined as greater than grade 4. DR was diagnosed according to the Early Treatment of Diabetic Retinopathy Study (ETDRS) criteria [13]. Other retinal diseases included optic atrophy, diabetic macular oedema, senile macular degeneration, high myopia macular degeneration, vascular retinopathy, or retinal detachment. If subjects had a combination of any one of the above diseases, we recorded the data as yes. Glycaemic control was categorized as normal (glycosylated haemoglobin $[\mathrm{HbA} 1 \mathrm{c}]<5.6$ ), good (HbA1c 5.6-7.0), fair (HbA1c 7.1-8.0), unsatisfactory (HbA1c 8.1-10.0), or poor $(\mathrm{HbA} 1 \mathrm{c}>10)$ [14]. Individuals were classified as lean (male, <20; female, <19), normal (male, 20-25; female, 19-24), overweight (male, 25-30; female, 24-29), or obese (male, $>30$; female, $>29$ ) according to the calculated BMI [15]. Educational status was classified as illiterate, primary school (1-9 years), or secondary school or higher ( $>9$ years).

\section{Statistical analysis}

Odds ratios (ORs) and 95\% confidence intervals (CIs) were calculated. Proportions were compared using the Chi-square test, and the means were compared using the $t$-test if parametric assumptions were fulfilled. Univariate analysis was used to examine whether there was a statistically significant association between each of the independent variables and URE. $P<0.05$ was considered statistically significant. To determine whether independent variables were predictive factors for URE, multiple logistic regression analysis was used to fit the best model for independent variables (all the variables analysed in the univariate analysis were included in multivariate models), with URE as the dependent variable. Population prevalence rates for URE were also calculated by direct age standardization to the 2000 Shanghai population census.

\section{Results}

In the study, 743 persons with diabetes aged $\geq 60$ years were enumerated, and 680 (response rates: 91.52\%; 95\% CI: $89.52 \%-93.52 \%)$ were examined. Of the 680 subjects, $31(4.56 \%)$ subjects had a history of cataract surgery and were either pseudophakic or aphakic. Because we mainly discussed URE, these participants were excluded. Therefore, data from 649 subjects were analysed. A comparison of demographic information and some of the variables in the subjects who were excluded or included in the study revealed that the subjects excluded from the study had a longer duration of diabetes than those included in the study (10.35 years vs. 7.57 years, $P=$ 0.018 ). There were no significant differences in the other variables between the two groups (Table 1).

Of the 649 subjects, 6 subjects were presenting blindness, and 156 subjects were presenting VI (VA of less than 6/12) in the better eye. The prevalence of mild, moderate, and severe VI was $14.02 \%, 9.40 \%$, and $0.62 \%$, respectively, and was $5.86 \%, 4.16 \%$, and $0.31 \%$, respectively, with refractive correction. After appropriate correction, only 4 subjects were blind, and 67 subjects still had VI. Notably, more than half of the visual impairment subjects $(89 / 156)$ could be corrected by wearing prescription spectacles (Fig. 1).

The prevalence rate of URE in the diabetic population is summarized in Table 2. Of the 649 subjects in our study, 99 (15.25\%) had URE. The calculated agestandardized prevalence rate of URE was $16.63 \%$ (95\% CI: 13.76-19.49). The prevalence of URE increased with age $(P<0.001)$. The prevalence was $9.20 \%$ in the youngest age group (60-69 years) and up to $32.89 \%$ in the oldest age group ( $\geq 80$ years). URE was also more common in women than in men $(P=0.025)$. The rate of URE among women was $17.88 \%$, and the value was $11.41 \%$ in men. Significant age-associated differences were noted in both women and men.

Among 525 examined subjects who did not have spectacle correction, the prevalence of URE was $15.05 \%$, which increased from $8.44 \%$ among those 60 to 69 years old to $34.43 \%$ among subjects greater than 80 years old $(P<0.001)$. Age-associated differences were also observed in women and men.

Among 124 subjects who habitually wore spectacles, the prevalence of URE among 60-69 year olds, 70-79 year olds, and greater than 80 year olds was $12.20 \%, 18.52 \%$, and $33.33 \%$, respectively $(P=0.044)$. No significant age or sex-associated differences were noted.

Table 3 shows the improvement in the participants' vision achieved by correcting their uncorrected or miscorrected refractive errors. Using appropriate spectacles improved the VA by at least one line in $44.84 \%$ (291/ 649 ) of the studied population and four lines or more in $5.55 \%(36 / 649)$. These figures were more pronounced among participants with VI. Among 71 participants whose VA was worse than $6 / 18$ in the better eye, 43 (60.56\%) had URE. In total, 49 subjects (69.01\%) obtained an improvement of at least one line after refractive correction, and $26(36.62 \%)$ experienced a four-line improvement in vision by wearing proper spectacles. The presenting VA was worse than 20/20 in the better eye of 518 participants, among whom $7.35 \%$ gained four lines of visual acuity with accurately prescribed spectacles. According to the definition, the 
Table 1 Comparison of subjects included in and excluded from this study

\begin{tabular}{|c|c|c|c|}
\hline & Excluded $(n=31)$ & Included $(n=649)$ & $p^{a}$ \\
\hline \multicolumn{4}{|l|}{ Age $($ mean $\pm S D)$} \\
\hline $60-69$ & $62.00 \pm 1.60$ & $62.87 \pm 2.86$ & 0.176 \\
\hline $70-79$ & $74.88 \pm 2.42$ & $74.23 \pm 2.64$ & 0.332 \\
\hline $80 \sim$ & $84.50 \pm 3.83$ & $84.26 \pm 5.32$ & 0.915 \\
\hline Gender & & & 0.060 \\
\hline Male & $22.58 \%$ & $40.52 \%$ & \\
\hline Female & $77.42 \%$ & $59.48 \%$ & \\
\hline Insurance status & & & 0.755 \\
\hline No & 0 & $0.92 \%$ & \\
\hline Yes & $100 \%$ & $99.08 \%$ & \\
\hline Occupation & & & 0.206 \\
\hline Farmer & $9.68 \%$ & $17.10 \%$ & \\
\hline Non-farmer & $90.32 \%$ & $82.90 \%$ & \\
\hline Level of education & & & 0.106 \\
\hline Illiteracy & $22.58 \%$ & $13.10 \%$ & \\
\hline Primary school & $54.84 \%$ & $47.46 \%$ & \\
\hline Secondary school or higher & $22.58 \%$ & $39.45 \%$ & \\
\hline Hypertension & $61.29 \%$ & $62.25 \%$ & 0.527 \\
\hline Hyperlipidaemia & $3.23 \%$ & $2.77 \%$ & 0.593 \\
\hline Smoker & $12.90 \%$ & $18.18 \%$ & 0.319 \\
\hline Alcohol use & $9.68 \%$ & $1.85 \%$ & 0.200 \\
\hline $\mathrm{BMI}($ mean $\pm \mathrm{SD})$ & $24.58 \pm 3.66$ & $24.58 \pm 3.43$ & 0.999 \\
\hline Duration of diabetes $(y)($ mean $\pm S D)$ & $10.35 \pm 6.98$ & $7.57 \pm 6.36$ & $0.018^{*}$ \\
\hline $\mathrm{HbA1c}(\mathrm{g} \%)($ mean $\pm \mathrm{SD})$ & $7.97 \pm 3.31$ & $7.58 \pm 2.19$ & 0.355 \\
\hline Spherical equivalent refractive error (SER) (mean \pm SD) & $-0.95 \pm 1.83$ & $-0.88 \pm 3.07$ & 0.843 \\
\hline Diabetic retinopathy & $9.68 \%$ & $4.62 \%$ & 0.186 \\
\hline
\end{tabular}

${ }^{\mathrm{a} C h i-s q u a r e}$ test was used for gender, insurance status, occupation, level of education, hypertension, hyperlipidaemia, smoking status, alcohol use, and diabetic retinopathy. Unpaired t-test was used for other variables ${ }^{*} P<0.05$

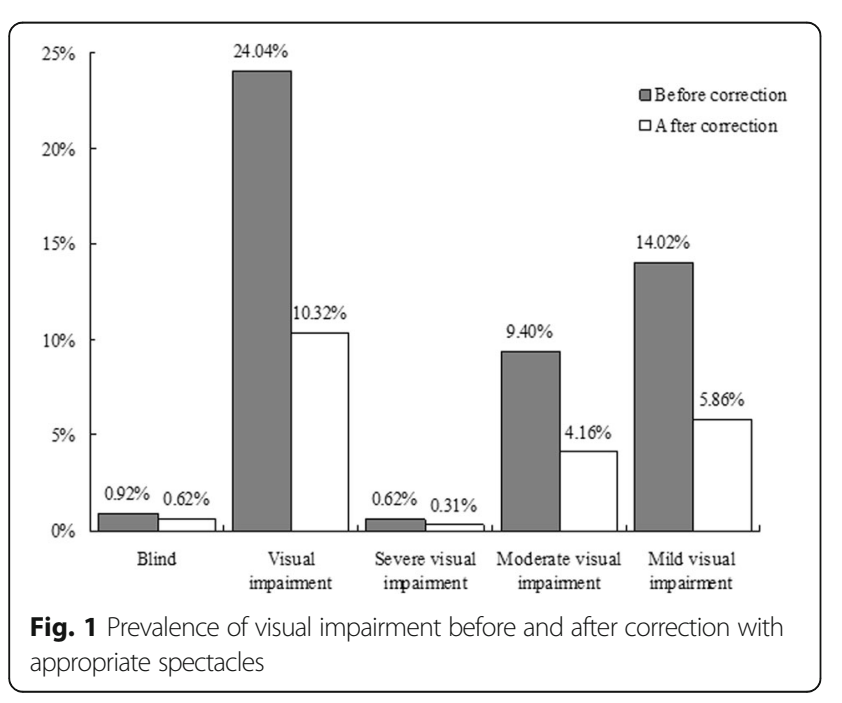

prevalence of URE in subjects whose presenting VA was worse than $6 / 18,20 / 40$, and $20 / 20$ in the better eye was $60.56 \%, 61.11 \%$, and $28.43 \%$, respectively.

In 124 subjects who wore spectacles for distance vision, nearly half (59/124) achieved visual acuity improvement by at least one line using appropriate spectacles; however, the prevalence of URE was still $16.13 \%(20 / 124)$ in subjects with glasses. Only 48 (38.71\%) subjects gained no benefit from a distance correction. In 525 subjects without spectacle correction, 233 (44.38\%) obtained an improvement of at least one line after refractive correction, and 33 (6.29\%) experienced a four-line improvement in vision by wearing proper spectacles. The prevalence of URE was $22.67 \%$ $(119 / 525)$ in subjects without glasses.

Table 4 shows the association between URE and the various clinical and biochemical variables. URE was significantly associated with older age (70-79 years: OR: 
Table 2 Prevalence rates of undercorrected refractive error

\begin{tabular}{|c|c|c|c|c|c|c|c|c|c|c|c|c|}
\hline & \multicolumn{4}{|c|}{ With glasses $n(\%)$} & \multicolumn{4}{|c|}{ Without glasses $n(\%)$} & \multicolumn{4}{|c|}{ Total n (\%) } \\
\hline & $N$ & $n$ & Prevalence Rate \% (95\% Cl) & $P$ & $N$ & $n$ & Prevalence Rate \% (95\% Cl) & $P$ & $N$ & $n$ & $\begin{array}{l}\text { Prevalence Rate \% (95\% } \\
\text { Cl) }\end{array}$ & $P$ \\
\hline All $(y)$ & & & & 0.044 & & & & $<0.001$ & & & & $<0.001$ \\
\hline $60-69$ & 82 & 10 & $12.20(5.11-19.28)$ & & 320 & 27 & $8.44(5.39-11.48)$ & & 402 & 37 & $9.20(6.38-12.03)$ & \\
\hline $70-79$ & 27 & 5 & $18.52(3.87-33.17)$ & 0.408 & 144 & 32 & $22.22(15.43-29.01)$ & $<0.001$ & 171 & 37 & $21.64(15.47-27.81)$ & $<0.001$ \\
\hline $80 \sim$ & 15 & 5 & $33.33(9.48-57.19)$ & 0.037 & 61 & 20 & $32.79(21.01-44.57)$ & $<0.001$ & 76 & 25 & 32.89 (23.54-44.88) & $<0.001$ \\
\hline Total & 124 & 20 & $16.13(9.66-22.60)$ & & 525 & 79 & 15.05 (11.99-18.11) & & 649 & 99 & 15.25 (12.49-18.02) & \\
\hline Men (y) & & & & 0.054 & & & & 0.011 & & & & 0.001 \\
\hline $60-69$ & 40 & 3 & $7.50(-0.66-15.66)$ & & 128 & 8 & $6.25(2.06-10.44)$ & & 168 & 11 & $6.55(2.81-10.29)$ & \\
\hline $70-79$ & 18 & 2 & $11.11(-3.41-25.63)$ & 0.650 & 50 & 11 & $22.00(10.52-33.48)$ & 0.002 & 68 & 13 & $19.12(9.77-28.46)$ & 0.004 \\
\hline $80 \sim$ & 9 & 3 & 33.33 (2.53-64.13) & 0.030 & 18 & 3 & $16.67(-0.55-33.88)$ & 0.140 & 27 & 6 & $22.22(6.54-37.90)$ & 0.007 \\
\hline Subtotal & 67 & 8 & $11.94(4.18-19.70)$ & & 196 & 22 & $11.22(6.81-15.64)$ & & 263 & 30 & $11.41(7.56-15.25)$ & \\
\hline Women (y) & & & & 0.212 & & & & $<0.001$ & & & & $<0.001$ \\
\hline $60-69$ & 42 & 7 & $16.67(5.40-27.94)$ & & 192 & 19 & $9.90(5.67-14.12)$ & & 234 & 26 & $11.11(7.08-15.14)$ & \\
\hline $70-79$ & 9 & 3 & $33.33(2.53-64.13)$ & 0.253 & 94 & 21 & $22.34(13.92-30.76)$ & 0.004 & 103 & 24 & $23.30(15.14-31.47)$ & 0.004 \\
\hline $80 \sim$ & 6 & 2 & $33.33(-4.39-71.05)$ & 0.328 & 43 & 17 & $39.53(24.92-54.15)$ & $<0.001$ & 49 & 19 & $38.78(25.13-52.42)$ & $<0.001$ \\
\hline Subtotal & 57 & 12 & $21.05(10.47-31.64)$ & & 329 & 57 & $17.33(13.24-21.41)$ & & 386 & 69 & $17.88(14.05-21.70)$ & \\
\hline$P(\operatorname{sex})$ & & & 0.171 & & & & 0.059 & & & & 0.025 & \\
\hline
\end{tabular}

2.72, 95\% CI: 1.66-4.48; 80 years: OR: 4.84, 95\% CI: 2.69-8.69), female gender (OR: 1.69, 95\% CI: 1.07-2.68), and myopia refractive error. A higher degree of myopia led to a higher risk for URE (low myopia: OR: $2.72,95 \%$ CI: 1.34-5.50; moderate myopia: OR: 4.60, 95\% CI: 1.97-10.78; high myopia: OR: 7.66, 95\% CI: 3.29-17.84). Of the diabetes-related variables, lens opacities status (OR: 3.81, 95\% CI: 2.22-6.51), diabetic retinopathy (OR: 2.52, 95\% CI: 1.12-5.68), combined with other retinal diseases (OR: 1.98, 95\% CI: 1.02-3.86), BMI index lower than normal (OR: 2.45, 95\% CI: 1.01-5.92), and a high glycated haemoglobin concentration ( $\geq 10.0$, OR: 4.41, 95\% CI: 1.77-11.02) were risk factors for URE.

In the final multiple logistic regression analysis controlling for all covariates, older age, female gender, non-farmer, myopia refractive error, lens opacities status, diabetic retinopathy, BMI index lower than normal, and poor glycaemic control were associated with higher

Table 3 Visual improvement after correcting refractive errors

\begin{tabular}{|c|c|c|c|c|}
\hline & Gained lines & Without glasses $n(\%)$ & With glasses $n(\%)$ & Total $n(\%)$ \\
\hline \multirow[t]{5}{*}{ Presenting vision worse than $6 / 18$ in the better eye $(n=71)$} & 0 lines & $14(28.57 \%)$ & $8(36.36 \%)$ & $22(30.99 \%)$ \\
\hline & $\geq 1$ line & $35(71.43 \%)$ & $14(63.64 \%)$ & $49(69.01 \%)$ \\
\hline & $\geq 2$ lines & $30(61.22 \%)$ & $13(59.09 \%)$ & $43(60.56 \%)$ \\
\hline & $\geq 3$ lines & $26(53.06 \%)$ & $9(40.91 \%)$ & $35(49.30 \%)$ \\
\hline & $\geq 4$ lines & $23(46.94 \%)$ & $3(13.64 \%)$ & $26(36.62 \%)$ \\
\hline \multirow[t]{5}{*}{ Presenting vision worse than $20 / 40$ in the better eye $(n=162)$} & 0 lines & $28(22.22 \%)$ & $11(30.56 \%)$ & $39(24.07 \%)$ \\
\hline & $\geq 1$ line & $98(77.78 \%)$ & $25(69.44 \%)$ & $123(75.93 \%)$ \\
\hline & $\geq 2$ lines & $79(62.70 \%)$ & $20(55.56 \%)$ & $99(61.11 \%)$ \\
\hline & $\geq 3$ lines & $50(39.68 \%)$ & $10(27.78 \%)$ & $60(37.04 \%)$ \\
\hline & $\geq 4$ lines & $33(26.19 \%)$ & $3(8.33 \%)$ & $36(22.22 \%)$ \\
\hline \multirow[t]{5}{*}{ Presenting vision worse than $20 / 20$ in the better eye $(n=518)$} & 0 lines & $178(43.31 \%)$ & $48(44.86 \%)$ & $226(46.57 \%)$ \\
\hline & $\geq 1$ line & $233(56.69 \%)$ & $59(55.14 \%)$ & $292(56.37 \%)$ \\
\hline & $\geq 2$ lines & $119(28.95 \%)$ & 34 (31.78\%) & 153 (28.43\%) \\
\hline & $\geq 3$ lines & 59 (14.36\%) & $14(13.08 \%)$ & 73 (14.22\%) \\
\hline & $\geq 4$ lines & $33(8.03 \%)$ & $3(2.80 \%)$ & $36(7.35 \%)$ \\
\hline
\end{tabular}


Table 4 Univariate and multivariate analysis of undercorrected refractive error in participants with Diabetes mellitus $(n=649)$

\begin{tabular}{|c|c|c|c|c|c|c|c|}
\hline & $N$ & $n$ & $\%(95 \% \mathrm{Cl})$ & $\begin{array}{l}\text { Univariate Odds Ratio (95\% } \\
\text { Cl) }\end{array}$ & $P$ & $\begin{array}{l}\text { Multivariate Odds Ratio (95\% } \\
\text { Cl) }\end{array}$ & $P$ \\
\hline Age, y & & & & & $<0.001$ & & $<0.001$ \\
\hline $60-69$ & 402 & 37 & $9.20(6.38-12.03)$ & 1 & & 1 & \\
\hline 70-79 & 171 & 37 & $21.64(15.47-27.81)$ & $2.72(1.66-4.48)^{\ddagger}$ & $<0.001$ & $3.28(1.78-6.07)^{\ddagger}$ & $<0.001$ \\
\hline $80 \sim$ & 76 & 25 & $32.89(22.33-43.46)$ & $4.84(2.69-8.69)^{\ddagger}$ & $<0.001$ & $3.93(1.85-8.35)^{\ddagger}$ & $<0.001$ \\
\hline Total & 649 & 99 & 15.25 (12.49-18.02) & & & & \\
\hline Age adjusted $\dagger$ & & & 16.63 (13.76-19.49) & & & & \\
\hline Gender & & & & & 0.026 & & 0.044 \\
\hline Male & 263 & 30 & $11.41(7.56-15.25)$ & 1 & & 1 & \\
\hline Female & 386 & 69 & $17.88(14.05-21.70)$ & $1.69(1.07-2.68)^{*}$ & & $1.79(1.02-3.15)^{*}$ & \\
\hline Occupation & & & & & 0.156 & & 0.049 \\
\hline Farmer & 111 & 18 & $16.22(9.36-23.07)$ & 1 & & 1 & \\
\hline Non-farmer & 538 & 135 & $25.09(21.43-28.76)$ & $1.59(0.84-3.02)$ & & $2.17(1.01-4.68)^{*}$ & \\
\hline Level of education & & & & & 0.083 & & 0.226 \\
\hline Illiteracy & 85 & 15 & $17.65(9.54-25.75)$ & 1 & & 1 & \\
\hline Primary school & 308 & 55 & $17.86(13.58-22.13)$ & $1.01(0.54-1.90)$ & 0.964 & $1.79(0.80-4.01)$ & 0.156 \\
\hline Secondary school or higher & 256 & 29 & $11.33(7.45-15.21)$ & $0.60(0.30-1.18)$ & 0.135 & $1.25(0.50-3.09)$ & 0.637 \\
\hline Insurance status & & & & & 0.923 & & 0.779 \\
\hline No & 6 & 1 & $16.67(-13.15-46.49)$ & 1 & & 1 & \\
\hline Yes & 643 & 98 & $15.24(12.46-18.02)$ & $0.90(0.10-7.78)$ & & $0.72(0.05-10.05)$ & \\
\hline Refractive error & & & & & $<0.0001$ & & $<0.001$ \\
\hline Emmetropia & 156 & 12 & $7.69(3.51-11.87)$ & 1 & & 1 & \\
\hline Hyperopia & 228 & 25 & $10.96(6.91-15.02)$ & $1.50(0.73-3.08)$ & 0.271 & $1.62(0.73-3.59)$ & 0.234 \\
\hline Low myopia & 168 & 31 & 18.45 (12.59-24.32) & $2.72(1.34-5.50)^{\dagger}$ & 0.005 & $2.99(1.36-6.55)^{\dagger}$ & 0.006 \\
\hline Moderate myopia & 53 & 14 & $24.62(14.55-38.28)$ & $4.60(1.97-10.78)^{\dagger}$ & 0.001 & $11.45(3.86-33.92)^{\ddagger}$ & $<0.001$ \\
\hline High myopia & 44 & 17 & $38.64(24.25-53.02)$ & $7.66(3.29-17.84)^{\ddagger}$ & $<0.0001$ & $18.91(5.97-59.92)^{\ddagger}$ & $<0.001$ \\
\hline Lens status & & & & & $<0.0001$ & & 0.001 \\
\hline Normal & 270 & 18 & 6.67 (3.69-9.64) & 1 & & 1 & \\
\hline Opacities & 379 & 81 & $21.37(17.24-25.50)$ & $3.81(2.22-6.51)^{\ddagger}$ & & $2.83(1.50-5.36)^{\dagger}$ & \\
\hline Diabetic retinopathy & & & & & 0.026 & & 0.035 \\
\hline No & 619 & 90 & 14.54 (11.76-17.32) & 1 & & 1 & \\
\hline Yes & 30 & 9 & $30.00(13.60-46.40)$ & $2.52(1.12-5.68)^{*}$ & & $2.99(1.08-8.30)^{*}$ & \\
\hline Combined with other retinal diseases & & & & & 0.045 & & 0.995 \\
\hline No & 597 & 86 & $14.41(11.59-17.22)$ & 1 & & 1 & \\
\hline Yes & 52 & 13 & $25.00(13.23-36.77)$ & $1.98(1.02-3.86)^{*}$ & & $1.00(0.40-2.48)$ & \\
\hline Duration of diabetes $(y)$ & & & & & 0.279 & & 0.223 \\
\hline$<5$ & 303 & 52 & $17.16(12.92-21.41)$ & 1 & & 1 & \\
\hline $5-10$ & 212 & 24 & $11.32(7.06-15.59)$ & $0.62(0.37-1.04)$ & 0.068 & $0.60(0.33-1.10)$ & 0.100 \\
\hline $10-15$ & 80 & 13 & $16.25(8.17-24.33)$ & $0.94(0.48-1.82)$ & 0.847 & $0.56(0.25-1.28)$ & 0.172 \\
\hline$\geq 15$ & 54 & 10 & $18.52(8.16-28.88)$ & $1.10(0.52-2.32)$ & 0.808 & $0.50(0.19-1.27)$ & 0.145 \\
\hline Drug use for diabetes & & & & & 0.279 & & 0.401 \\
\hline No & 89 & 17 & $19.10(10.93-27.27)$ & 1 & & 1 & \\
\hline Yes & 560 & 82 & $14.64(11.71-17.57)$ & $0.73(0.41-1.30)$ & & $0.73(0.36-1.51)$ & \\
\hline
\end{tabular}


Table 4 Univariate and multivariate analysis of undercorrected refractive error in participants with Diabetes mellitus $(n=649)$ (Continued)

\begin{tabular}{|c|c|c|c|c|c|c|c|}
\hline & $N$ & $n$ & $\%(95 \% \mathrm{Cl})$ & $\begin{array}{l}\text { Univariate Odds Ratio (95\% } \\
\text { Cl) }\end{array}$ & $P$ & $\begin{array}{l}\text { Multivariate Odds Ratio (95\% } \\
\text { Cl) }\end{array}$ & $P$ \\
\hline History of diabetic retinopathy therapy & & & & & 0.053 & & 0.205 \\
\hline No & 630 & 93 & $14.76(11.99-17.53)$ & 1 & & 1 & \\
\hline Yes & 19 & 6 & $31.58(10.68-52.48)$ & $2.67(1.00-7.19)$ & & $2.36(0.63-8.90)$ & \\
\hline $\mathrm{HbA1c}(\mathrm{g} \%)$ & & & & & $<0.001$ & & 0.003 \\
\hline$<5.6$ & 70 & 7 & $10.00(2.97-17.03)$ & 1 & & 1 & \\
\hline $5.6-7.0$ & 260 & 31 & $11.92(7.98-15.86)$ & $1.22(0.51-2.90)$ & 0.655 & $0.74(0.28-1.96)$ & 0.546 \\
\hline $7.1-8.0$ & 138 & 18 & $13.04(7.42-18.66)$ & $1.35(0.54-3.40)$ & 0.525 & $0.85(0.30-2.43)$ & 0.765 \\
\hline $8.1-10.0$ & 105 & 18 & $17.14(9.93-24.35)$ & $1.86(0.73-4.73)$ & 0.191 & $1.21(0.43-3.41)$ & 0.721 \\
\hline$\geq 10.0$ & 76 & 25 & $32.89(22.33-43.46)$ & $4.41(1.77-11.02)^{\dagger}$ & 0.001 & $3.18(1.11-9.12)^{*}$ & 0.031 \\
\hline $\mathrm{BMI}\left(\mathrm{kg} / \mathrm{m}^{2}\right)$ & & & & & 0.211 & & 0.096 \\
\hline Normal & 299 & 42 & 14.05 (10.11-17.99) & 1 & & 1 & \\
\hline Lean & 28 & 8 & $28.57(11.84-45.30)$ & $2.45(1.01-5.92)^{*}$ & 0.047 & $3.44(1.19-9.91)^{*}$ & 0.022 \\
\hline Overweight & 268 & 39 & 14.55 (10.33-18.77) & $1.04(0.65-1.67)$ & 0.864 & $1.07(0.61-1.90)$ & 0.810 \\
\hline Obese & 54 & 10 & $18.52(8.16-28.88)$ & $1.39(0.65-2.97)$ & 0.395 & $1.74(0.69-4.39)$ & 0.244 \\
\hline Hypertension & & & & & 0.325 & & 0.894 \\
\hline No & 245 & 33 & $13.47(9.19-17.74)$ & 1 & & 1 & \\
\hline Yes & 404 & 66 & 16.34 (12.73-19.94) & $1.25(0.80-1.97)$ & & $0.96(0.55-1.69)$ & \\
\hline Hyperlipidaemia & & & & & 0.620 & & 0.577 \\
\hline No & 631 & 97 & 15.37 (12.56-18.19) & 1 & & 1 & \\
\hline Yes & 18 & 2 & $11.11(-3.41-25.63)$ & $0.69(0.16-3.04)$ & & $0.61(0.11-3.42)$ & \\
\hline Smoker & & & & & 0.780 & & 0.529 \\
\hline No & 531 & 82 & $15.44(12.37-18.52)$ & 1 & & 1 & \\
\hline Yes & 118 & 17 & $14.41(8.07-20.74)$ & $0.92(0.52-1.62)$ & & $0.67(0.19-2.37)$ & \\
\hline Alcohol use & & & & & 0.791 & & 0.715 \\
\hline No & 537 & 81 & $15.08(12.06-18.11)$ & 1 & & 1 & \\
\hline Yes & 112 & 18 & $16.07(9.27-22.87)$ & $1.08(0.62-1.88)$ & & $1.26(0.36-4.38)$ & \\
\hline Cardiovascular disease & & & & & 0.487 & & 0.832 \\
\hline No & 595 & 89 & 14.96 (12.09-17.82) & 1 & & 1 & \\
\hline Yes & 54 & 10 & $18.52(8.16-28.88)$ & $1.29(0.63-2.66)$ & & $1.10(0.44-2.74)$ & \\
\hline Distance eyeglasses wearing & & & & & 0.703 & & 0.011 \\
\hline No & 525 & 79 & 15.05 (11.99-18.11) & 1 & & 1 & \\
\hline Yes & 124 & 20 & $16.13(9.66-22.60)$ & $1.09(0.64-1.85)$ & & $0.34(0.15-0.78)^{*}$ & \\
\hline
\end{tabular}

${ }^{*} P<0.05$

$+P<0.01$

$\ddagger P<0.001$

levels of URE. In contrast, wearing distance eyeglasses during the eye examination was a protective factor for URE. Other variables, such as level of education, insurance status, and duration of diabetes were not significantly associated with URE.

\section{Discussion}

Visual Impairment and diabetes are both very common in the older population $[2,3,11]$. In response to the global initiative for elimination of avoidable blindness raised by the WHO, Vision 2020, it is necessary to understand the major causes of VI in this special group and how to avoid these risks. As a survey of URE in the elderly diabetic population, our study showed that if refractive correction was available, the prevalence of mild, moderate, and severe VI could be reduced from $14.02 \%, 9.40 \%$, and $0.62 \%$, respectively, to $5.86 \%, 4.61 \%$, and $0.31 \%$, respectively. Our study also found that for diabetic subjects with presenting 
vision worse than 6/18, the occurrence of URE was $60.56 \%$, and more than one-third of them (36.62\%) gained four or more lines of visual improvement. For presenting vision worse than $20 / 40$, these two indicators were $76.1 \%$ and $62.0 \%$, respectively. Hence, these results indicated that a significant proportion of visual loss was due to inadequately corrected refractive error.

To the best of our knowledge, this is the first study to document URE among senior individuals with diabetes in urban China, and the rate of URE was $16.63 \%$. The prevalence in the present study was somewhat higher than in Hong Kong [4]. Other studies on general populations have reported various rates. In a review, the rate of URE ranged from $9.55 \%$ to $21.7 \%$ [9, 15-18] (Table 5). Although the age of recruitment, the definition for URE, the sampling strategies, the geography, and the race were different from those in the present study, a similar phenomenon was noted. URE was the major cause of presenting blindness and VI both in general populations and among diabetic people in China.

In our study, some risk factors for URE in the general population were also identified in the diabetic population, i.e., older age, female gender, non-farmer, myopic refractive error, and not wearing distance eyeglasses $[9$, 15-18]. Some risk factors that were shown in the general population, such as unemployment [17] and lower education level [15-17], were not observed in the present study among the diabetic population. Older age, as the most significant risk factor, was also observed in the Hong Kong study involving a population with diabetes [4]. In the general population, the probable explanation is that older subjects are more likely to have a lower level of education and lower economic status, which has been estimated to be associated with a higher prevalence of URE $[15-17,19,20]$. However, in the diabetic population, another primary cause of URE might be specific physical barriers caused by complications of diabetes, such as diabetic cardiovascular complications, diabetic peripheral neuropathy, and diabetic nephropathy, which have a higher incidence in the elderly. Females in our survey had a higher prevalence of URE than males. This disparity may be related to Chinese traditional culture. In China, females are given less attention than males in the family. Therefore, females have a lower educational level, leading to a lower socioeconomic status and reduced awareness of health care [8].

Our study shows that a higher degree of myopia is a significant risk factor for URE in diabetic people, with odds of 18.91 times for high myopia and 11.45 times for moderate myopia. In mild myopia, undercorrection would be helpful for near work among elderly subjects in daily life. However, in moderate and high myopia, the possible explanation for higher prevalence of URE is that they think the decrease in VA is due to the primary disease, i.e., diabetes. Second, the idea that undercorrection of myopia could inhibit myopia progression is prevalent among myopic persons.

In China, farmer is always a symbol of lower-income and lower education level, which makes people think farmer will be a risk factor of URE. However, farmer also means a healthy lifestyle in China. These individuals spend more time on outdoor activities and have less near distance work, which results in a lower prevalence of myopia in the farmer population [21]. As mentioned above, myopia was a significant risk factor of URE in the current analysis. Hence, farmers had a lower prevalence of URE in this survey.

We should pay more attention to a number of factors associated with diabetes, such as diabetic retinopathy, significant lens opacities, lower BMI, and worsening of glycaemic control (HbA1c $(\mathrm{g} \%) \geq 10.0)$. As is well known, DR is a major cause of blindness and VI in the diabetic population [22, 23]. However, in our survey, the prevalence of URE was shown to be higher in subjects with DR than in subjects without DR $(30.00 \%$ vs. $14.54 \%)$, indicating that impaired vision could be improved even in individuals with DR. This finding could be explained by the fact that although DR can lead to a decrease in VA, this ocular complication is still primary in most subjects. URE is the leading cause of VI in individuals with DR. For example, in a study from Denmark, DR was found in $7 \%$ of diabetic patients and was not sight-threatening in any of the cases [24]. Individuals with DR often misunderstand that their vision loss is caused by ocular complications of diabetes and that nothing can be done to improve the situation, completely ignoring the possibility of URE.

In our study, persons with cataracts had nearly three-fold greater odds of having URE than persons without cataracts. In the general population, the view that cataract-induced vision loss can be corrected by surgery or appropriate refractive correction has been accepted by most people. However, almost all the health education for diabetes in Shanghai emphasizes the dangers of ocular complications in diabetes, which makes diabetic subjects think that their vision loss is inevitable and irreversible. In fact, a myopic shift can occur due to the expansion of the lens, and the vision loss caused by this period of cataracts may be completely corrected by spectacles.

Unexpectedly, in our study, lower BMI was found to be associated with a higher risk of URE. In the general population, lower BMI may represent a healthy lifestyle, healthy diet, and sufficient physical activities; however, in the diabetic population, a lower BMI may be seen as a sign of a catabolic state and perhaps be a precursor to death. Hence, a possible explanation is that lower BMI diabetic subjects have relatively serious physical complications that 
Table 5 Comparison of prevalence and risk factors of undercorrected refractive error between the present study and various published studies

\begin{tabular}{|c|c|c|c|c|c|c|c|}
\hline Study & $\begin{array}{l}\text { Sample } \\
\text { Size }\end{array}$ & Population & Age & $\begin{array}{l}\text { Undercorrection } \\
\text { in Study Population } \\
(\%)\end{array}$ & $\begin{array}{l}\text { Undercorrection } \\
\text { among Participants } \\
\text { with Refractive Error } \\
(\%)\end{array}$ & Definitions & $\begin{array}{l}\text { Multivariate Risk } \\
\text { Factors }\end{array}$ \\
\hline $\begin{array}{l}\text { Present } \\
\text { study }\end{array}$ & 649 & $\begin{array}{l}\text { Diabetes } \\
\text { Chinese }\end{array}$ & $\begin{array}{l}\text { Mean: } \\
68.37 \pm 8.22 \\
\text { Range: } 60-100\end{array}$ & $16.63 \%$ & $\begin{array}{l}10.96 \% \text { of } \\
\text { hyperopia subjects } \\
23.40 \% \text { of myopic } \\
\text { subjects }\end{array}$ & $\begin{array}{l}\text { Presenting visual } \\
\text { acuity }<20 / 40 \text { (Best-corrected } \\
\text { VA -Presenting VA) } \geq 2 \\
\text { lines improvement }\end{array}$ & $\begin{array}{l}\text { Older age, female } \\
\text { gender, non-farmer, } \\
\text { myopia, lens opacities } \\
\text { status, DR, lower BMI, } \\
\text { poor glycaemic } \\
\text { control, not wearing } \\
\text { spectacles }\end{array}$ \\
\hline $\begin{array}{l}\text { Hong Kong } \\
\text { Correctable Visual } \\
\text { Impairment Study [4] }\end{array}$ & 2301 & $\begin{array}{l}\text { Type } 2 \\
\text { diabetes } \\
\text { mellitus }\end{array}$ & $\begin{array}{l}\text { Mean: } 61.4 \pm \\
10.5 \\
\text { Range: } 23-92\end{array}$ & $7.30 \%$ & NA & $\begin{array}{l}\text { Presenting } V A<6 / 18 \text { that } \\
\text { improved to no impairment } \\
\text { ( } \geq 6 / 18) \text { after refractive } \\
\text { correction }\end{array}$ & $\begin{array}{l}\text { Older age, more } \\
\text { advanced stage of DR }\end{array}$ \\
\hline $\begin{array}{l}\text { Tanjong Pagar } \\
\text { Survey [9] }\end{array}$ & 1152 & $\begin{array}{l}\text { General } \\
\text { Singaporean } \\
\text { Chinese }\end{array}$ & $40-79$ & $21.7 \%$ & NA & $\begin{array}{l}\text { Presenting VA }<20 / 40 \\
\text { in the better eye (Best- } \\
\text { corrected VA- Presenting } \\
\text { VA) } \geq 2 \text { lines } \\
\text { improvement }\end{array}$ & $\begin{array}{l}\text { Older age, lower } \\
\text { education level, not } \\
\text { wearing spectacles, } \\
\text { cataracts }\end{array}$ \\
\hline SiMES [15] & 3115 & $\begin{array}{l}\text { General } \\
\text { Singaporean } \\
\text { Malays }\end{array}$ & $\begin{array}{l}\text { Mean: } 58 \pm \\
11 \\
\text { Range: } 40-80\end{array}$ & $20.4 \%$ & $\begin{array}{l}28.7 \% \text { of hyperopia } \\
\text { subjects } \\
28.9 \% \text { of myopic } \\
\text { subjects }\end{array}$ & $\begin{array}{l}\text { Presenting } V A<20 / 40 \\
\text { in the better eye (Best- } \\
\text { corrected VA- Presenting } \\
V A) \geq 2 \text { lines improvement }\end{array}$ & $\begin{array}{l}\text { Older age, female sex, } \\
\text { lower education level }\end{array}$ \\
\hline $\begin{array}{l}\text { Shihpai Eye } \\
\text { Study [16] }\end{array}$ & 1361 & $\begin{array}{l}\text { General } \\
\text { Chinese }\end{array}$ & $\begin{array}{l}\text { Mean: } 72.2 \\
\text { Range: } \geq 65\end{array}$ & $9.55 \%$ & $\begin{array}{l}11.3 \% \text { of hyperopic } \\
\text { subjects } \\
34.4 \% \text { of myopic } \\
\text { subjects }\end{array}$ & $\begin{array}{l}\text { Presenting } V A<20 / 40 \text { in } \\
\text { the better eye (Best- } \\
\text { corrected VA -Presenting } \\
\text { VA) } \geq 2 \text { lines improvement } \\
\text { in better eye }\end{array}$ & $\begin{array}{l}\text { Older age, non- } \\
\text { emmetropic eye, not } \\
\text { wearing spectacles } \\
\text { and lower level of } \\
\text { education }\end{array}$ \\
\hline LALES [17] & 6129 & $\begin{array}{l}\text { General } \\
\text { Latinos }\end{array}$ & $\begin{array}{l}\text { Mean: } 54.9 \\
\pm 10.8 \\
\text { Range: } \geq 40\end{array}$ & $15.1 \%$ & NA & $\begin{array}{l}\text { (Best-corrected VA- } \\
\text { presenting VA) } \geq 2 \text { lines } \\
\text { improvement in better eye }\end{array}$ & $\begin{array}{l}\text { Older age, lack of } \\
\text { health insurance, } \\
\text { lower education level, } \\
\text { lower BMI, being } \\
\text { unemployed }\end{array}$ \\
\hline BMES [18] & 3654 & $\begin{array}{l}\text { General } \\
\text { Caucasians }\end{array}$ & $\begin{array}{l}\text { Mean: } 66.2 \\
\text { Range: } 49- \\
97\end{array}$ & $10.2 \%$ & $\begin{array}{l}53.9 \% \text { of hyperopic } \\
\text { subjects } \\
12.7 \% \text { of myopic } \\
\text { subjects }\end{array}$ & $\begin{array}{l}\text { Presenting VA }<20 / 40 \text { (Best- } \\
\text { corrected VA - presenting } \\
\text { VA) improvement of } \geq 2 \\
\text { lines in the better eye }\end{array}$ & $\begin{array}{l}\text { Older age, living } \\
\text { alone, occupations of } \\
\text { trade and labourer, } \\
\text { receipt of a } \\
\text { government pension, } \\
\text { hyperopia and } \\
\text { duration from the last } \\
\text { eye examination }\end{array}$ \\
\hline
\end{tabular}

prevent them from attending regular healthcare visits and receiving optometric service. Another explanation is that compared with obese and overweight individuals, lower BMI subjects have less awareness of their medical problems and health issues.

Glycosylated haemoglobin is stable and is a reliable to reflect the average blood glucose levels nearly 8 to 12 weeks before detection; as such, it is the gold standard for monitoring diabetes. In our study, worsening of glycaemic control resulted in a higher risk of URE by nearly 3-fold because hyperglycaemia causes a transient myopic shift in poorly controlled diabetic subjects $[14,25,26]$. Our data suggest that adults with diabetes should pay greater attention to the control and systemic management of their diabetes and also visit the eye service and optometric service immediately when they are experiencing loss of vision to determine the cause and subsequent treatment to reduce the risk of URE.

These risk factors for URE, especially factors associated with diabetes, have important implications in planning public health strategies for urban China, where government health insurance is widely available. Risk factors associated with diabetes remind us that lack of knowledge and awareness of refractive error may be the primary cause of URE in the diabetic population. We recommend establishing comprehensive eye care services and improving health education programmes, especially optometric service and knowledge of URE in the diabetic population. Most eye screening programmes and health education for people with diabetes in Shanghai emphasize cataracts and DR, ignoring the importance of refractive error. 
Our study showed that wearing spectacles is a protective factor against URE. A supply of suitable glasses is the most efficient and economical way to improve vision and reduce the prevalence of URE. We suggest improving the quality of optometric service and reducing the cost of purchasing spectacles to encourage the use of spectacles. Although the cost of refraction is already covered by the health insurance system in Shanghai, the cost of spectacles is still expensive, and this may be an important reason why refractory error remains uncorrected in some individuals.

This study has several limitations. First, this study was conducted only among the senior diabetes population aged 60 or above. However, diabetes is also a common metabolic disorder in adults aged 20-60 years, and it is meaningful to explore the prevalence of URE and associated risk factors in this age group. Studies including this age group are warranted. Second, the study was conducted in a single centre, which might not be similar to other geographic areas in Shanghai. Third, data were based on known diabetes only. Patients with undiagnosed diabetes might lead to a potential source of bias. Fourth, glycated haemoglobin values and type of diabetes were not available. Considering that there may be different risk factors between persons with type 1 diabetes and type 2 diabetes, additional studies may be needed to elucidate any differences.

\section{Conclusion}

In conclusion, the present study found that approximately $16.63 \%$ of diabetic adults aged 60 years and above had URE. URE is also a significant cause of VI among diabetic adults. Apart from some risk factors of URE both in the general population and diabetic population, such as older age, female gender, non-farmer, myopic refractive error, and not wearing distance eyeglasses, we should pay more attention to the risk factors associated with diabetes, such as $\mathrm{DR}$, significant lens opacities, lower BMI, and worsening of glycaemic control $(\mathrm{HbA} 1 \mathrm{c}(\mathrm{g} \%) \geq 10.0)$. Health education programmes should disseminate basic optometric knowledge and give correct guidance to the diabetic population. Regular screening, including a simple refractive assessment, is needed to reduce the magnitude of URE in subjects with diabetes. Persons with diabetes ought to be more aware that poor vision is often correctable.

\section{Abbreviations}

BCVA: Best-corrected visual acuity; Cl: Confidence interval; DR: Diabetic retinopathy; Mild VI: Mild visual impairment; Mod VI: Moderate visual impairment; OR: Odds ratio; SER: Spherical equivalent refractive error; SVI: Severe visual impairment; URE: Undercorrected refractive error; VA: Visual acuity; Vl: Visual impairment

\section{Acknowledgements}

The authors thank the Shanghai Municipal Health Bureau and Shanghai Shen Kang Hospital Development Center for their financial support and the Center of Disease Control and Prevention of Baoshan District for their support of registration. We are also very grateful to the study participants.

\section{Funding}

This study was supported by the projects "Shanghai Public Health Personnel Training Programme Research Fund" from Shanghai Municipal Health Bureau (08GWQ036), "Expanded application of the screening of blinding diseased in the senior population aged $\geq 60$ years in the digital community" (SHDC 12010212), and "Exploration of the municipal health care resources in the community in order to avoid blind eye disease (SHDC 12007628)" from the Shanghai Shen Kang Hospital Development Center.

\section{Availability of data and materials}

All the data supporting our findings are contained within the manuscript.

\section{Authors' contributions}

MJZ participated in the design of this epidemiologic study, conducted and analysed the data, contributed to the interpretation of the results and discussion, and wrote and edited the manuscript. XWT and RZ contributed to the conception and design of this epidemiologic study and collected research data. $\mathrm{XGH}$ and HJZ participated in the research data collection. JFZ participated in the design of this epidemiologic study, contributed to the interpretation of the results and discussion, and gave final approval of the version to be published. All authors have read and approved the final manuscript.

\section{Ethics approval and consent to participate}

The current investigation followed the tenets of the Declaration of Helsinki and was approved by the Ethical Committee of the Shanghai Eye Disease Prevention and Treatment Center. All participants signed written informed consent before participating in the study.

\section{Consent for publication}

Not applicable.

\section{Competing interests}

The authors declare that they have no competing interests.

\section{Publisher's Note}

Springer Nature remains neutral with regard to jurisdictional claims in published maps and institutional affiliations.

\section{Author details}

${ }^{1}$ Shanghai Eye Disease Prevention and Treatment Center, No. 380 Kangding Road, Jingan District, Shanghai 200040, China. ${ }^{2}$ Shanghai Hospital Development Center, Shanghai 200040, China. ${ }^{3}$ Center of Disease Control and Prevention of Baoshan District, Shanghai 201901, China.

Received: 16 June 2017 Accepted: 20 November 2017

Published online: 28 November 2017

\section{References}

1. IDF Diabetes Atlas Group. Update of mortality attributable to diabetes for the IDF Diabetes Atlas: estimates for the year 2013. Diabetes Res Clin Pract. 2015;109:461-5.

2. $\quad X u$ Y, Wang L, He J, Bi Y, Li M, Wang T, Wang L, Jiang Y, Dai M, Lu J, Xu M, Li Y, Hu N, Li J, Mi S, Chen CS, Li G, Mu Y, Zhao J, Kong L, Chen J, Lai S, Wang W, Zhao W, Ning G, 2010 China Noncommunicable Disease Surveillance Group. Prevalence and control of diabetes in Chinese adults. JAMA. 2013;310:948-59.

3. Yang W, Lu J, Weng J, Jia W, Ji L, Xiao J, Shan Z, Liu J, Tian H, Ji Q, Zhu D, Ge J, Lin L, Chen L, Guo X, Zhao Z, Li Q, Zhou Z, Shan G, He J, China National Diabetes and Metabolic Disorders Study Group. Prevalence of diabetes among men and women in China. N Engl J Med. 2010;362:1090-101.

4. Fung MM, Yap MK, Cheng KK. Correctable visual impairment among people with diabetes in Hong Kong. Clin Exp Optom. 2010;93:453-7.

5. Centers for Disease Control and Prevention (CDC). Correctable visual impairment among persons with diabetes-United States, 1999-2004. MMWR Morb Mortal Wkly Rep. 2006:55:1169-72.

6. Klein BE, Moss SE, Klein R, Lee KE, Cruickshanks KJ. Associations of visual function with physical outcomes and limitations 5 years later in an older population: the Beaver Dam eye study. Ophthalmology. 2003;110:644-50.

7. Heasley K, Buckley JG, Scally A, Twigg P, Elliott DB. Falls in older people: effects of age and blurring vision on the dynamics of stepping. Invest Ophthalmol Vis Sci. 2005;46:3584-8. 
8. Crews JE, Chou CF, Zhang X, Zack MM, Saaddine JB. Health-related quality of life among people aged $\geq 65$ years with self-reported visual impairment: findings from the 2006-2010 behavioral risk factor surveillance system. Ophthalmic Epidemiol. 2014;21:287-96.

9. Zhu M, Tong X, Zhao R, He X, Zhao H, Liu M, Zhu J. Visual impairment and spectacle coverage rate in Baoshan district, China: population-based study. BMC Public Health. 2013;13:311.

10. Saw SM, Foster PJ, Gazzard G, Friedman D, Hee J, Seah S. Undercorrected refractive error in Singaporean Chinese adults: the Tanjong Pagar survey. Ophthalmology. 2004;111:2168-74.

11. Vision impairment and blindness. http://www.who.int/mediacentre/ factsheets/fs282/en/.

12. Wang L, Huang W, He M, Zheng Y, Huang S, Liu B, Jin L, Congdon NG, He $M$. Causes and five-year incidence of blindness and visual impairment in urban Southern China: the Liwan Eye Study. Invest Ophthalmol Vis Sci. 2013;54:4117-21.

13. Ezelum C, Razavi H, Sivasubramaniam S, Gilbert CE, Murthy GV, Entekume G, Abubakar T, Nigeria National Blindness and Visual Impairment Study Group. Refractive error in Nigerian adults: prevalence, type, and spectacle coverage. Invest Ophthalmol Vis Sci. 2011;52:5449-56.

14. Early Treatment Diabetic Retinopathy Study Research Group. Fundus photographic risk factors for progression of diabetic retinopathy. ETDRS report number 12. Ophthalmology. 1991;98(5 Suppl):823-33.

15. Rosman M, Wong TY, Tay WT, Tong L, Saw SM. Prevalence and risk factors of undercorrected refractive errors among Singaporean Malay adults: the Singapore Malay Eye Study. Invest Ophthalmol Vis Sci. 2009;50:3621-8.

16. Kuang TM, Tsai SY, Hsu WM, Cheng CY, Liu JH, Chou P. Correctable visual impairment in an elderly Chinese population in Taiwan: the Shihpai Eye Study. Invest Ophthalmol Vis Sci. 2007:48:1032-37.

17. Varma R, Wang MY, Ying-Lai M, Donofrio J, Azen SP; Los Angeles Latino Eye Study Group. The prevalence and risk indicators of uncorrected refractive error and unmet refractive need in Latinos: the Los Angeles Latino Eye Study. Invest Ophthalmol Vis Sci. 2008;49:5264-73.

18. Thiagalingam S, Cumming RG, Mitchell P. Factors associated with undercorrected refractive errors in an older population: the Blue Mountains Eye Study. Br J Ophthalmol. 2002;86:1041-5.

19. Zhang X, Gregg EW, Cheng YJ, Thompson TJ, Geiss LS, Duenas MR, Saaddine JB. Diabetes mellitus and visual impairment: national health and nutrition examination survey, 1999-2004. Arch Ophthalmol. 2008;126:14217

20. Ryskulova A, Turczyn K, Makuc DM, Cotch MF, Klein RJ, Janiszewski R. Selfreported age-related eye diseases and visual impairment in the United States: results of the 2002 national health interview survey. Am J Public Health. 2008:98:454-61.

21. Huang J, Wen D, Wang Q, McAlinden C, Flitcroft I, Chen H, Saw SM, Chen H, Bao F, Zhao Y, Hu L, Li X, Gao R, Lu W, Du Y, Jinag Z, Yu A, Lian H, Jiang Q, Yu Y, Qu J. Efficacy Comparison of 16 Interventions for Myopia Control in Children: A Network Meta-analysis. Ophthalmology. 2016;123:697-708.

22. Echouffo-Tcheugui JB, Ali MK, Roglic G, Hayward RA, Narayan KM. Screening intervals for diabetic retinopathy and incidence of visual loss: a systematic review. Diabet Med. 2013;30:1272-92.

23. Younis N, Broadbent DM, Vora JP, Harding SP; Liverpool Diabetic Eye Study. Incidence of sightthreatening retinopathy in patients with type 2 diabetes in the Liverpool Diabetic Eye Study: a cohort study. Lancet. 2003;361:195200.

24. Bek T, Lund-Andersen $H$, Hansen AB, Johnsen KB, Sandbaek A, Lauritzen T. The prevalence of diabetic retinopathy in patients with screen-detected type 2 diabetes in Denmark: the ADDITION study. Acta Ophthalmol. 2009; 87:270-4.

25. Sonmez B, Bozkurt B, Atmaca A, Irkec M, Orhan M, Aslan U. Effect of glycemic control on refractive changes in diabetic patients with hyperglycemia. Cornea. 2005;24:531-7.

26. Rani PK, Raman R, Rachapalli SR, Kulothungan V, Kumaramanickavel G, Sharma T. Prevalence of refractive errors and associated risk factors in subjects with type 2 diabetes mellitus SN-DREAMS, report 18. Ophthalmology. 2010;117:1155-62.

\section{Submit your next manuscript to BioMed Central and we will help you at every step:}

- We accept pre-submission inquiries

- Our selector tool helps you to find the most relevant journal

- We provide round the clock customer support

- Convenient online submission

- Thorough peer review

- Inclusion in PubMed and all major indexing services

- Maximum visibility for your research

Submit your manuscript at www.biomedcentral.com/submit 